\section{Trinexapac-ethyl Affects Kentucky Bluegrass Root Architecture}

\author{
Jeffrey S. Beasley and Bruce E. Branham ${ }^{1}$ \\ Department of Natural Resources and Environmental Sciences, University of \\ Illinois, 1102 South Goodwin Avenue, Urbana, IL 61801
}

\author{
Loretta M. Ortiz-Ribbing ${ }^{2}$ \\ U.S. Depatment of Agriculture, Agricultural Research Service, Department of \\ Crop Sciences, University of Illinois, 1102 South Goodwin Avenue, Urbana, \\ IL 61801
}

Additional index words. PGRs, root surface area, shoot growth, root length, Azure A

\begin{abstract}
Trinexapac-ethyl (TE) [4-(cyclopropyl-a-hydroxy-methylene)-3,5-dioxocyclohexanecarboxylic acid ethyl ester] effects on turfgrass root architecture are not known. It has been postulated that PGR application could cause photoassimilate that is normally used for shoot growth to be funneled to root growth. This study evaluated the effects of a single TE application on kentucky bluegrass (KBG) root and shoot growth for seven weeks. Individual KBG plants were grown in a hydroponic system and harvested weekly. At each harvest, tiller height, tiller number, and color ratings were recorded. Estimates of total root length (TRL), root surface area (SA), and average root diameter were measured using the WinRhizo system. Trinexapac-ethyl reduced plant height for 4 weeks followed by a period of postinhibition growth enhancement. Trinexapac-ethyl increased tiller number over the course of the study and slightly enhanced plant color. Trinexapacethyl reduced TRL and SA $48 \%$ and $46 \%$ at 1 week after treatment (WAT) followed by an accelerated growth rate 1 to 4 WAT. Trinexapac-ethyl had no effect on root diameter. On a tiller basis, TE initially reduced TRL and SA $30 \%$ and $31 \%$, respectively. Total root length per tiller and root surface area per tiller were reduced by TE treatment, but by 7 WAT, those differences were no longer significant. Initial reductions in TRL and SA per tiller may reduce tiller competitiveness for water and nutrients. Based on data for TRL and SA per tiller, shoot and root growth must be considered in total to fully understand TE effects on plant growth. Field research is needed to corroborate results from hydroponic-studies and examine the effect of various TE rates and multiple applications on turfgrass root and shoot growth.
\end{abstract}

Exogenously applied plant growth regulators (PGRs) such as trinexapac-ethyl (TE) are widely used in highly maintained turfgrass areas (Watschke etal., 1992). Trinexapac-ethyl, a late stage gibberellin inhibitor (Adams et al., 1992), has been shown to reduce clipping production for both warm and cool-season turfgrasses (Fagerness and Yelverton, 2000; Lickfeldt et al., 2001). Because PGRs reduce vertical shoot growth, it has been theorized that root growth may be enhanced through basal photoassimilate transport (Kaufmann et al., 1983).

Studies concerning PGR effects on turfgrass root growth have reported conflicting results (Ervin and Koski, 2001a; Fagerness and Yelverton, 2001; Marcum and Jiang, 1997). In a study by Ervin and Koski (2001a), no changes were found in root mass for TE-treated kentucky bluegrass (Poa pratensis L.) in combination with nitrogen and wear treatments. Fagerness and Yelverton (2001) reported similar results with sequential applications of TE at various rates on Penncross creeping bentgrass (Agrostis stolonifera L.); however, they reported reductions in root mass from paclobutrazol applied at

Received for publication 17 Nov. 2004. Accepted for publication 9 Feb. 2005.

${ }^{1}$ To whom reprint requests should be addressed; e-mailbbranham@uiuc.edu. twice the label rate. In contrast, McCarty et al. (2004) found up to a $45 \%$ increase in root mass ofTE-treated ultra-dwarfbermudagrass [ $\mathrm{Cyn}$ odon dactylon (L.) Pers.] compared to other PGRs while increasing rates of paclobutrazol and flurprimidol reduced root mass. Marcum and Jiang (1997) examined the effect of several PGRs on tall fescue (Festuca arundincea Schreb.) rooting. They reported paclobutrazol reduced tall fescue maximum rooting depth, total root length(TRL), and root length density (RLD) at two depths while TE only reduced TRL and RLD in one of two experiments. In a study evaluating TE for use on shaded turfs, Goss et al. (2002) found no differences in root mass, but did report increased tillering for TE-treated creeping bentgrass resulting in a reduced root/shoot ratio on a tiller basis.

Most PGR turfgrass root studies have drawn conclusions based on mass rather than root architecture. However, several studies have examined the impact of PGRs on shoot morphology (Ervin and Koski, 2001b; Heckman et al., 2001). Using light microscopy, Ervin and Koski (2001b) showed individual TE-treated KBG leaves to have increased cell density per leaf as a result of shorter, thicker cells. These morphological changes have been accompanied by increasing specific leaf weight (Gaussion et al., 1997; Heckman et al., 2001). Other studies have reported increased canopy densities both visually and using tiller counts (Ervin and Koski, 1998; Fagerness and Yelverton, 2000).

Leaf morphological alterations due to PGR applications raise the question "Do PGRs affect root architecture?" Changes in rooting resulting from PGR application may affect nutrient and water uptake required for plant sustainability (Field and Whitford, 1982). In turn, root function may influence overall plant growth and stress tolerance. Few published studies have reported the effects of PGRs on turfgrass root architecture.

The widespread adoption of the use of trinexapac-ethyl on highly managed turfgrass calls for more complete information on the effects of TE on turfgrass growth. This study examined shoot growth and root architecture of kentucky bluegrass following a single TE application.

\section{Materials and Methods}

Kentucky bluegrass ('Moonlight') was seeded into a 1 perlite : 3 organic matter potting mixture and placed in the greenhouse. Six weeks after germination, individual KBG plants were removed, roots were thoroughly washed, and plants were transplanted into a hydroponic system.

The hydroponic system consisted of four separate rectangular containers measuring $(25 \times 40 \times 15 \mathrm{~cm})$ with lids containing 18 openings, $0.785 \mathrm{~cm}^{2}$ per circular opening, on a 5-cm grid. Plants were stabilized using cylindrical foam plugs with roots submersed in an aerated, modified Hoagland solution with 0.25 strength of $\mathrm{N}$ (Hoagland and Arnon, 1938). Nutrient solution was changed weekly and $\mathrm{pH}$ was adjusted to 6.5 every $3 \mathrm{~d}$. Two high-pressure sodium lamps provided 800 to $900 \mu \mathrm{mol} \cdot \mathrm{m}^{-2} \cdot \mathrm{s}^{-1}$ PAR for a $16-\mathrm{h}$ photoperiod. Hydroponic containers were shifted daily to provide more uniform irradiance levels. A water-filled plexiglass tray was placed between the high-pressure sodium lamps and turfgrass plants to reduce infrared heating.

Three weeks after transplanting, KBG plants were selected based on uniformity of root and tiller development. Half of the plants in a container were treated with TE while the other half served as controls. The label rate of TE, $0.27 \mathrm{~kg} \cdot \mathrm{ha}^{-1}$ a.i., was applied in 375 L water/ha using a chamber sprayer (Allen Machine Works, Midland, Mich.) with air as the propellant.

One control and one TE-treated plant per replication were harvested weekly for 7 weeks. Plants were rated for color on a scale of 1 to 9 (1 representing completely brown, 9 exceptional green color, and 6 as minimally acceptable). Plant height and tiller number were recorded. Roots were excised from the shoot as close to the crown as possible and placed into a (by volume) 25 ethanol : $75 \mathrm{H}_{2} \mathrm{O}$ solution for preservation. Samples were stored at $4{ }^{\circ} \mathrm{C}$ until root analysis.

The WinRhizo system (version 5.0A, Regent Instruments Inc., Quebec, Canada) was used to analyze stored root samples. Guidelines for image analysis followed a combination of 
Table 1. Plant height, as a percent of control, tiller number, and color rating of TE-treated kentucky bluegrass plants 1 to 7 weeks after treatment (WAT).

\begin{tabular}{lcccccc}
\hline & Ht $(\%$ of control $)$ & \multicolumn{2}{c}{ Tiller no. } & & \multicolumn{2}{c}{ Color rating $^{z}$} \\
\cline { 3 - 4 } \cline { 5 - 6 } WAT & TE & TE & Control & & TE & Control \\
\hline 1 & $52.4^{* * *}$ & 2.6 & 3.3 & 7.4 & 7.1 \\
2 & $42.0^{* * *}$ & 4.1 & 5.4 & $7.8^{* *}$ & 7.2 \\
3 & $59 .^{* * *}$ & 10.0 & 6.0 & 7.2 & 7.0 \\
4 & 107.1 & $21.0^{* *}$ & 13.5 & 7.1 & 7.1 \\
5 & $118.7^{* * *}$ & $27.2^{* * *}$ & 15.8 & 7.2 & 7.1 \\
6 & $117.0^{* *}$ & $21.4^{* *}$ & 13.6 & & 7.1 & 7.1 \\
7 & 95.3 & $32.2^{* *}$ & 22.3 & & $7.3^{* *}$ & 6.8 \\
\hline
\end{tabular}

${ }^{2}$ Color ratings are on a scale of 1 to $9(1=$ brown color, $9=$ exceptional green color, and $6=$ minimally acceptable color).

$*, * * * * * *$ Significant at $0.1,0.05$, and 0.001 probability levels, respectively.

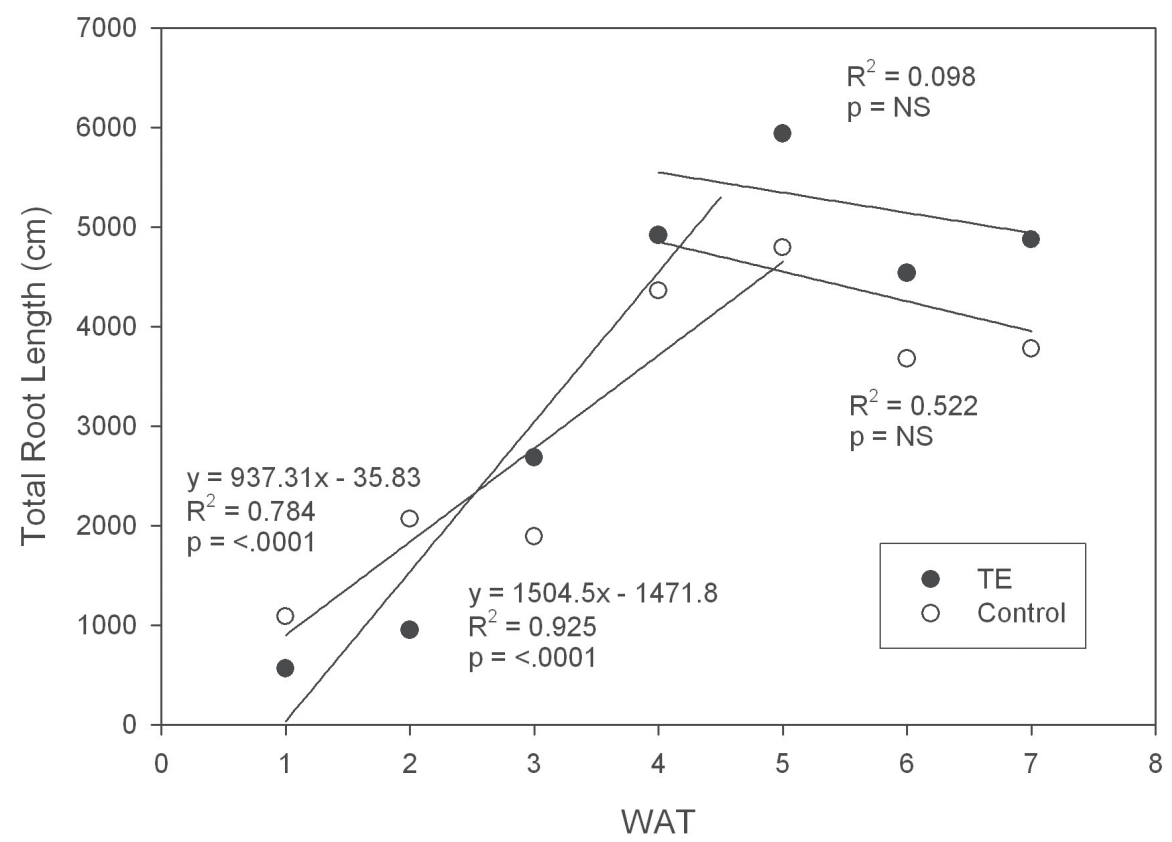

Fig. 1. Total root length $(\mathrm{cm})$ for TE-treated and untreated (control) kentucky bluegrass plants 1 to 7 weeks after treatment (WAT). Slopes between the two regression lines are significantly different 1 to 4 WAT (TE vs. control slopes for TRL, $P=0.0618$ ). Slopes of both regression lines from 4 to 7 WAT are not significantly different than 0 (week $\times$ treatment, $P=0.4893)$.

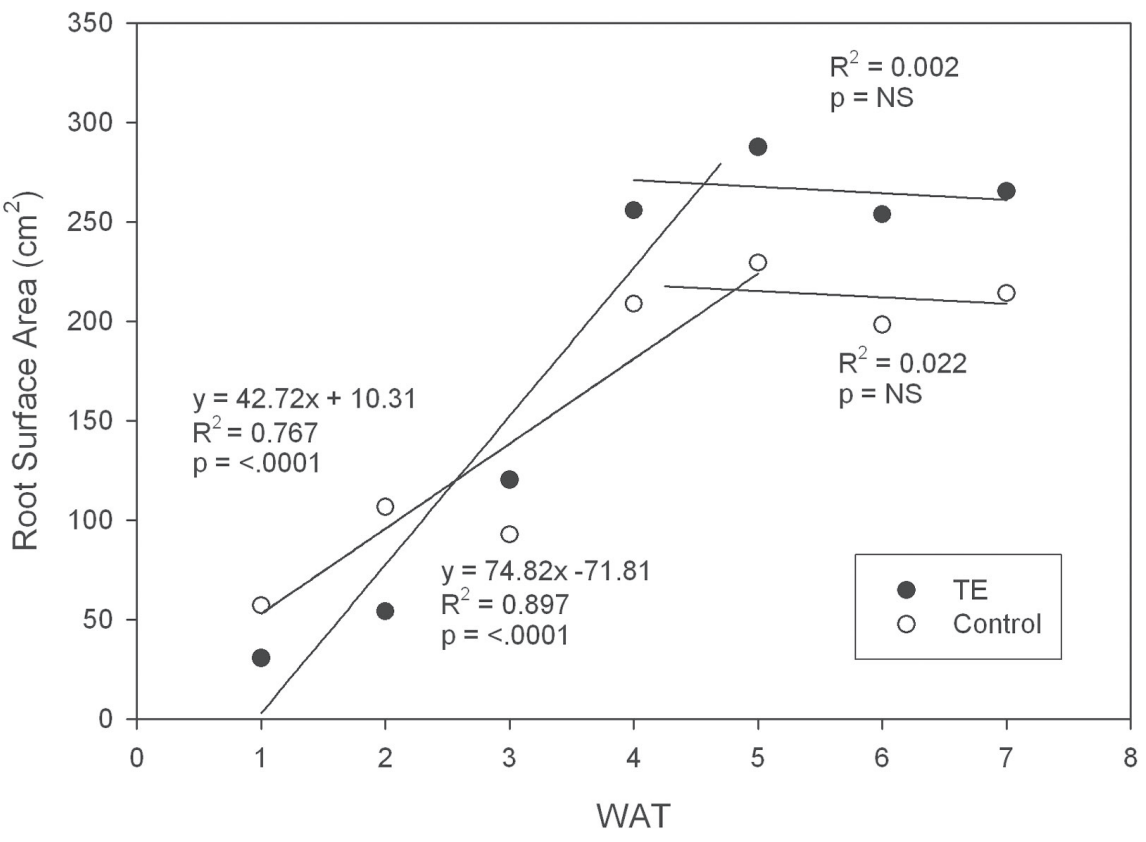

Fig. 2. Root surface area $\left(\mathrm{cm}^{2}\right)$ for TE-treated and untreated (control) kentucky bluegrass plants 1 to 7 weeks after treatment (WAT). Slopes between the two regression lines are significantly different for 1 to 4 WAT (TE vs. control slopes for SA, $P=0.0316$ ). Slopes of both regression lines from 4 to 7 WAT are not significantly different than 0 (week $\times$ treatment, $P=0.9560)$. procedures outlined by Bouma et al. (2000) and Costa et al. (2001). To provide maximum root contrast, roots were dyed in a solution of Azure $\mathrm{A}\left(100 \mathrm{mg} \cdot \mathrm{L}^{-1}\right)$ for $24 \mathrm{~h}$ before analysis. Roots were washed using deionized water and arranged in a water-filled tray to minimize root overlapping. In later weeks, larger root samples were cut into $10-\mathrm{cm}$ samples to reduce root volume and overlap. Roots were scanned at 500 dots per inch (dpi)) and total root length (in $\mathrm{cm}$ ), diameter (in $\mathrm{mm}$ ), and surface area (in $\mathrm{cm}^{2}$ ) were measured.

The experimental design was a randomized complete block with three replications. The experiment was repeated. Harvest weeks were analyzed using repeated measures with $\mathrm{TE}$ as the fixed factor over time. Regression analysis was used when appropriate. Data were analyzed using the mixed procedure in SAS (SAS, 2003).

\section{Results and Discussion}

Data from both experiments were combined because experiment $\times$ treatment $\times$ date interactions were not significant. Trinexapacethyl reduced KBG plant height $40 \%$ to $59 \%$ per week for 3 WAT after which plant height increased compared to control plants (Table 1). During the postinhibition growth period, plant height increased on average $18 \%$ per week. After the inhibition period, tiller number increased more rapidly for TE-treated plants through the remainder of the study. Plant color was slightly enhanced by TE.

Total root length (TRL) and surface area (SA) exhibited similar growth patterns (Figs. 1 and 2). Total root length and SA increased linearly for 4 WAT, but further increases were minimal. Trinexapac-ethyl treated plants had a reduction of $48 \%$ and $46 \%$ for TRL and SA 1 WAT. However, TRL and SA from TE treatment increased to a greater extent from 1 to 4 WAT than the controls (TE vs. control slopes for TRL $P=0.0618,1 \mathrm{df}$; TE vs. control slopes for SA P $=0.0316,1 \mathrm{df}$ ). Beyond 4 WAT, TRL and SA growth rates for TE-treated and control plants were similar. No differences in average root diameter were detected.

On a per tiller basis, TRL and SA of TEtreated and control plants decreased linearly with time (Figs. 3 and 4). For TE-treated plants, TRL and SA per tiller were reduced $30 \%$ and $31 \%$, respectively compared to control plants 1 WAT. Rates of TRL and SA reduction per tiller were greatest for control plants and declined when compared to TE-treated plant TRL and SA estimates over time (TE vs. control slopes for TRL per tiller $P=0.00201 \mathrm{df}$; TE vs. control slopes for SA per tiller $P=0.01131 \mathrm{df}$ ).

Many researchers and turfgrass practitioners often ask how a particular treatment affects root growth or shoot growth. This research illustrates the complexity of plant root growth research. Both root and shoot growth should be measured to obtain an accurate representation of the effects of exogenously applied PGRs. From this study, root growth (TRL and SA) on a plant community basis could indicate an increase in rooting for TEtreated plants. However, TE-induced tillering 
resulted in reduced TRL and SA per tiller. A similar finding was reported by Goss et al. (2002) with reductions in root mass per tiller for TE-treated creeping bentgrass grown under reduced light conditions.

Increased tiller number and reduced TRL and SA per tiller from a TE application could limit individual tiller development through lowered nutrient and water uptake. As a result, TE may affect turfgrass sward intra-competition under field conditions.

On a plant community basis, TE-treated KBG plant height and tillering followed a typical pattern reported in many TE-treated turfgrass studies (Ervin and Koski, 2001a;
Fagerness et al., 2002). Root and shoot growth of TE-treated plants had similar growth patterns: an initial reduction in TRL and SA was followed by a period of increased growth Because TE had no effect on average root diameter, increases in TRL and SA are due to existing vertical growth and/or root initiation.

Differences in root architecture and tillering between TE-treated and control plants may be the result of altered carbon exchange rates (CERs) and/or photoassimilate partitioning. Other agronomic commodities treated with PGRs have shown decreased and/or increased CERs as well as altered photoassimilate partitioning (El-Hodairi et al., 1988; Huang et al.

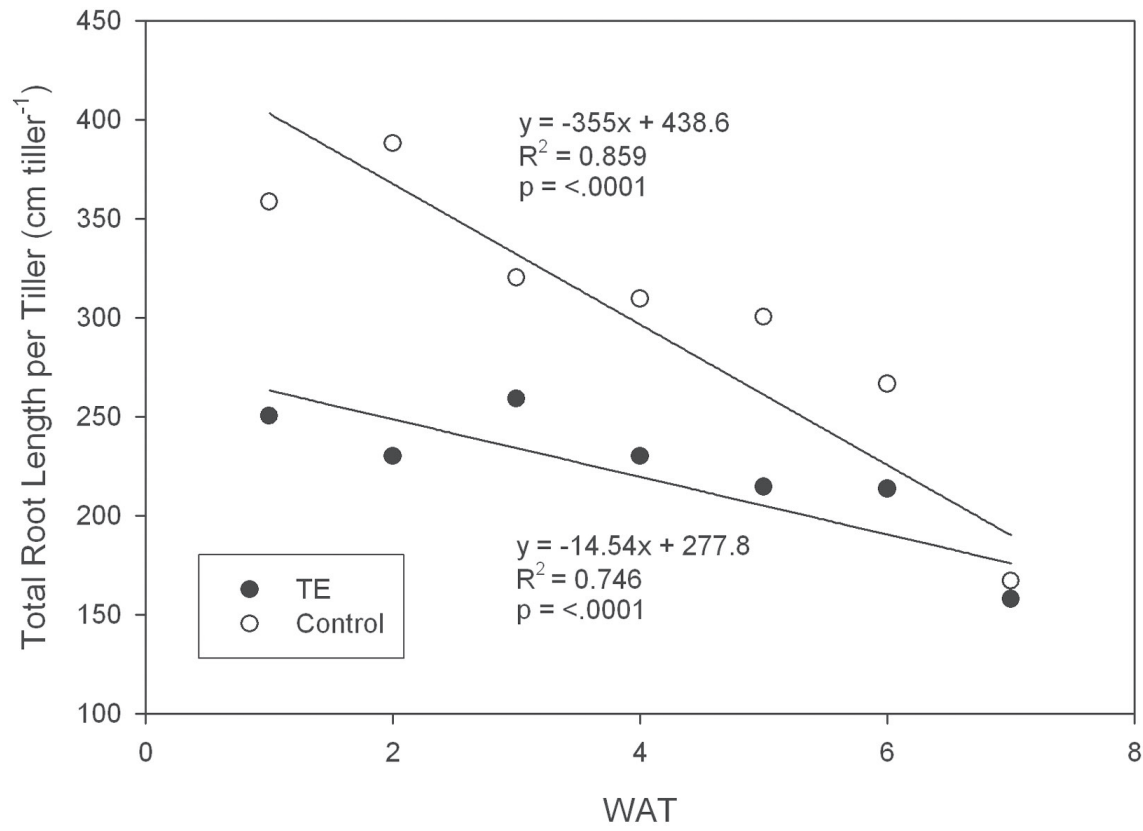

Fig. 3. Total root length (in $\mathrm{cm}$ ) per tiller for TE-treated and untreated (control) kentucky bluegrass 1 to 7 weeks after treatment (WAT). Slopes between the two regression lines are significantly different $(P=0.0020)$.

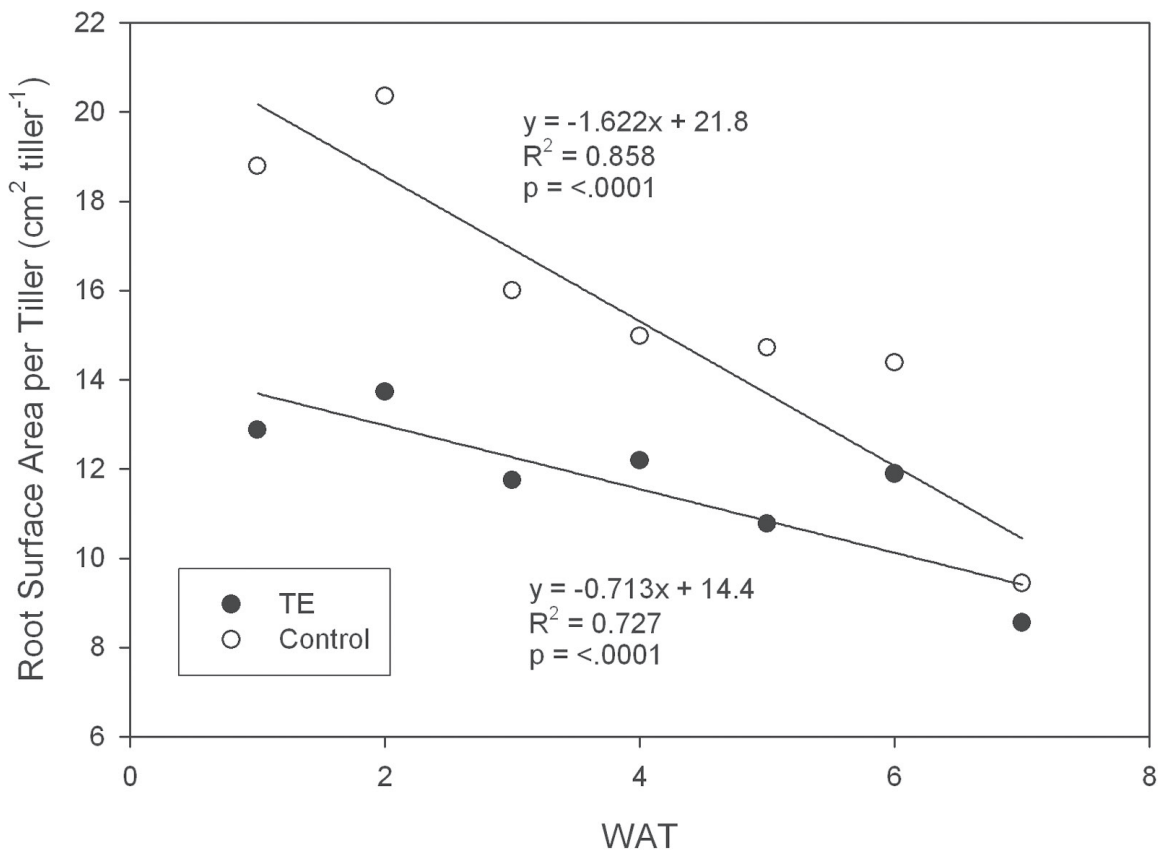

Fig. 4. Root surface area $\left(\mathrm{in}_{\mathrm{cm}}^{2}\right)$ per tiller for TE-treated and untreated (control) kentucky bluegrass 1 to 7 weeks after treatment (WAT). Slopes between the two regression lines are significantly different $(P=0.0133)$
1995; Hunter and Proctor, 1994). Trinexapacethyl temporarily reduced CER followed by a period of increased CER in cool season turfgrasses (Beasley, 2005). Changes in photoassimilate partitioning in kentucky bluegrass have been reported for several PGRs (Hanson and Branham, 1987).

Use of ahydroponics system for plant growth allowed a simple method to obtain shoot and root data, but provided limited space for advanced studies. Methods used for this study do not represent field conditions. Single plant hydroponics yields limited insight into effects on sward root and shoot dynamics. Further research is needed to assess the effects of TE rates and multiple application schedules on turfgrass root and shoot growth in addition to other physiological parameters under field conditions.

\section{Literature Cited}

Adams, R., E. Kerber, K. Pfister, and E.W. Weiler. 1992. Studies on the action of the new growth retardant CGA 163'935 (cimectacarb), p. 818-827. In: C.M. Karssen, L.C. van Loon, and D. Vreugdenhil (eds.). Progress in plant growth regulation. Kluwer Academic Publ., Dordrecht, The Netherlands.

Beasley, J.S. 2005. Growth responses of trinexapac-ethyl and paclobutrazol treated cool season turfgrasses. $\mathrm{PhD}$ diss. Univ. Ill.

Bouma, T.J., K.L. Nielsen, and B. Koutstaal. 2000. Sample preparation and scanning Protocol for computerized analysis of root length and diameter. Plant Soil 288:185-196.

Costa, C., L.M. Dwyer, C. Hamel, D.F. Muamba, W.L. Wang, L. Nantais, and D.L. Smith. 2001. Root contrast enhancement for measurement with optical scanner-based image analysis. Can. J. Bot. 79:23-29.

El-Hodairi, M.H., A.E. Canham, W.R. Buckley. 1988. The effects of paclobutrazol on growth and the movement of ${ }^{14} \mathrm{C}$-labelled assimilates in 'Red Delicious' apple seedlings. J. Hort. Sci. 63:575-581.

Ervin,E.H. andA.J. Koski. 2001a. Kentuckybluegrass growth responses to trinexapac-ethyl, traffic, and nitrogen. Crop Sci. 41:1871-1877.

Ervin, E.H. and A.J. Koski. 2001b. Trinexapac-ethyl increases kentucky bluegrass leaf cell density and chlorophyll concentration. Hortscience 36:787-789.

Ervin, E.H. and A.J. Koski. 1998. Growth responses of Lolium perenne L. to trinexapac-ethyl. HortScience 33:1200-1202.

Fagerness, M.J. andF.H.Yelverton. 2001.Plant growth regulator and mowing height effects on seasonal root growth of penncross creeping bentgrass. Crop Sci. 41:1901-1905.

Fagerness, M.J. and F.H. Yelverton. 2000. Tissue production and quality of 'Tifway'Bermudagrass as affected by seasonal application patterns of trinexapac-ethyl. Crop Sci. 40:493-497.

Field, R.J. and A.R. Whitford. 1982. Effect of simulated mowing on the translocation of mefluidide in perennial ryegrass (Lolium perenne L.) Weed Res. 22:177-181.

Gaussoin, R.E., B.E. Branham, and J.A. Flore. 1997. Carbon dioxide exchange rate and chlorophyll content of turfgrasses treated with fluriprimidol or mefluidide. J. Plant Growth Regulat. 16:73-78.

Goss, R.M., J.H. Baird, S.L. Kelm, and R.N. Calhoun. 2002. Trinexapac-ethyl and nitrogen effects on creeping bentgrass grown under reduced light conditions. Crop Sci. 42:472-479.

Hanson, K.V. and B.E. Branham. 1987. Effects of 
four growth regulators on photosynthate partitioning in 'Majestic' kentucky bluegrass. Crop Sci. 27:1257-1260.

Heckman, N.L., G.L. Horst, and R.E. Gaussoin. 2001. Influence of trinexapac-ethyl on specific leaf weight and chlorophyll content of Poa pratensis. Intl. Turf Soc. Res. J. p. 287.

Hoagland, D.R. and D.I.Arnon. 1938. Growing plants without soil by the water-culture method. p. 39 . Calif. Agr. Expt. Sta. Circ. 347.

Huang, W.D., T. Shen, Z.H. Han, and S. Liu. 1995. Influence of paclobutrazol on photosynthesis rate and dry matter partitioning in the apple tree. J.
Plant Nutr.18:901-910.

Hunter, D.M. and J.T.A. Proctor. 1994. Paclobutrazol reduces photosynthetic carbon uptake rate in grapevines. J. Amer. Soc. Hort. Sci. 119:486-491.

Kauffman, J.E., J.J. Sandbrink, S.J. Stehling, and P.S. Thibodeau. 1983. Efficacy of six plant growth regulators on Michigan roadside grasses, p. 128. In: Agronomy abstracts. ASA, Madison, Wis.

Lickfeldt, D.W.,D.S. Gardner, B.E. Branham, and T.B. Voigt. 2001. Implications of repeated trinexapacethyl applications on kentucky bluegrass. Agron. J. 93:1164-1168.
Marcum, K.B. and H. Jiang. 1997. Effects of plant growth regulators on tall fescue rooting and water use. J. Turfgrass Mgt. 2:13-27.

McCarty, B., P. McCullough, and H. Liu. 2004. Ultradwarf bermudagrass: How sensitive is it to PGRs. Turfgrass Trends Feb:1-3.

SAS Institute. 2003. The SAS system for Windows. Release 9.1. SAS Inst., Cary, N.C.

Watschke, T.L., M.G. Prinster, and J.M. Breuninger. 1992. Plant growth regulators and turfgrass management, p. 557-588. In: Waddington et al. (eds.). ASA-CSSA-SSSA Turfgrass Agron. Monogr. 32. 